\title{
Professional nursing practice: environment and emotional exhaustion among intensive care nurses ${ }^{1}$
}

\author{
Marcia Raquel Panunto² \\ Edinêis de Brito Guirardello3
}

Objective: to evaluate the characteristics of the professional nursing practice environment and its relationship with burnout, perception of quality of care, job satisfaction and the intention to leave the job in the next 12 months. Method: cross-sectional study with a quantitative approach to data. The sample was composed of 129 nurses working in adult Intensive Care Units from a region in the interior of São Paulo, Brazil. Results: The structural equation modeling, using path analysis, revealed that characteristics of the environment influence job satisfaction, perception of quality of care, and having an intention to leave their job, when mediated by emotional exhaustion. Nurses with limited autonomy, poor control over their practice, and poor relationships with physicians, experience a greater level of emotional exhaustion, which can negatively influence their perception of quality of care, job satisfaction and an intention to abandon their jobs. Conclusion: the mediating role of emotional exhaustion may negatively influence care delivery. Therefore, there is a need to adopt strategies to minimize this condition among nurses.

Descriptors: Health Facility Environment; Burnout; Nursing; Intensive Care Unit.

\footnotetext{
${ }^{1}$ Paper extracted from Doctoral Dissertation "Ambiente da Prática Profissional da Equipe de Enfermagem em Terapia Intensiva" presented to Faculdade de Ciências Médicas, Universidade Estadual de Campinas, Campinas, SP, Brazil.

2 RN, MSc, Hospital de Clínicas, Universidade Estadual de Campinas, Campinas, SP, Brazil.

${ }^{3} \mathrm{PhD}$, Associate Professor, Faculdade de Enfermagem, Universidade Estadual de Campinas, Campinas, SP, Brazil.
} 


\section{Introduction}

Environments that favor the practice of nurses have been studied ${ }^{(1-3)}$ since some hospitals were acknowledged as being able to more easily attract and retain professionals and, consequently, provide high quality healthcare. These facilities have been called "magnet hospitals"(1).

The presence of certain characteristics in professional nursing practice environments can promote the development of professionals and favor safe practices, among them, the philosophy of quality-focused care, interdisciplinary cooperation, responsibility with professional authority, promotion of nursing leadership, support for the professional development of nurses, and the development of cooperative relationships among health workers ${ }^{(4)}$.

The facilities that possess such attributes encourage improved outcomes for patients, for the nursing staff, and for the institution itself $f^{(2,5)}$. In turn, professionals working in negative environments are dissatisfied with their jobs ${ }^{(6-7)}$, more frequently report an intention to leave their jobs ${ }^{(7-8)}$, and are more exposed to burnout ${ }^{(6-7,9)}$, a condition that negatively affects professionals and impacts the characteristics of the environment and patient outcomes ${ }^{(9)}$.

Burnout is a syndrome characterized by emotional exhaustion, depersonalization, and low personal accomplishment. It mainly affects health workers due to their continuous exposure to patients afflicted by chronic diseases ${ }^{(10)}$.

In the hospital context, professionals working in Intensive Care Units (ICUs) are responsible to provide care to patients in an environment associated with complex care and the imminent risk of death, experiencing situations of death and mourning daily at the risk of becoming more susceptible to emotional repercussions and stress, leading to burnout (11).

It is a challenge to identify and analyze the aspects involved in the professional nursing practice environment, but such an endeavor seeks to propose improved working conditions and promote changes in hospital environments. In this context, this study's objective was to assess the characteristics of the professional nursing practice environment and its relationship with nurses' experience of burnout, job satisfaction, perception of quality care, and intention to leave the job in the next 12 months.

\section{Method}

This cross-sectional study with a quantitative approach was conducted in the adult ICUs of 17 public, private and philanthropic hospitals in the interior of São Paulo, Brazil. The population included 144 nurses, 129 of which composed the sample according to the inclusion criteria: exclusively performing care activities and having three months or more of experience in the current hospital. Those on vacation or on leave were not included.

The study project was approved by the Institutional Board Review (Process No. 362/2011) and the individuals who agreed to participate signed free and informed consent forms.

Data were collected through three self-reported instruments: a form addressing personal and professional characterization and a characterization of the working environment; the Brazilian short version of the Nursing Work Index - Revised (NWI-R); and the Malash Burnout Inventory (MBI). Data were collected from November $24^{\text {th }} 2011$ to January $31^{\text {st }} 2012$.

The NWI-R is designed to measure the presence of certain characteristics in the working environment that contribute to the professional practice of nurses ${ }^{(2)}$. The instrument has already been translated and adapted for the Brazilian culture(12) and contains 57 items, 15 of which were selected and distributed conceptually into three subscales: autonomy, nurse-physician relationships, and control over work environment. Ten out of these 15 items were grouped and gave origin to a fourth subscale: organizational support.

A four-point Likert scale was used. The lower the score, the higher the presence of positive attributes, conducive to the practice of professionals. Scores below 2.5 indicate favorable professional practice environments while scores above 2.5 indicate unfavorable environments.

The reliability of NWI-R was assessed using Cronbach's alpha, which indicated a satisfactory internal consistency for all the subscales ${ }^{(13)}$. The following alpha values were obtained in this study: 0.78 for autonomy; 0.73 for control over work environment; 0.82 for nursephysician relationships; and 0.80 for organizational support.

The MBI, already validated for the Brazilian culture, is designed to measure the physical and emotional exhaustion of workers in relation to work ${ }^{(14)}$. It contains 22 statements, the scores of which are defined according to the frequency professionals experience certain situations: 1 - never; 2 - rarely; 3 -sometimes; 4 - often; 5 - always. It assesses burnout based on three different constructs: emotional exhaustion, low personal accomplishment, and depersonalization. The 
results concerning the reliability of these constructs are satisfactory(14-15). In this study, the following internal consistency was obtained: 0.90 for emotional exhaustion; 0.54 for depersonalization; and 0.70 for low personal accomplishment.

Data were analyzed with the help of an expert. The Statistical Package for Social Sciences (SPSS) version 15.0 was used for the descriptive analysis (average, standard deviation, frequencies, and percentages) of the individuals' characteristics. The Linear Structure Relations (LISREL) software, version 8.7, was used for the multivariate analysis, through which Structural
Equation Modeling (SEM) was performed. SEM was used because it is able to measure, explain and preview the degree of relationship among the statistical variables, through the establishment of causal relationships for each set of dependent variables ${ }^{(16)}$.

The model proposed in this study was composed of exogenous variables (autonomy, control over work environment, nurse-physician relationships) and of endogenous variables (emotional exhaustion, depersonalization, personal accomplishment, job satisfaction, perception of quality of care, and intention to leave their job) (Figure 1).

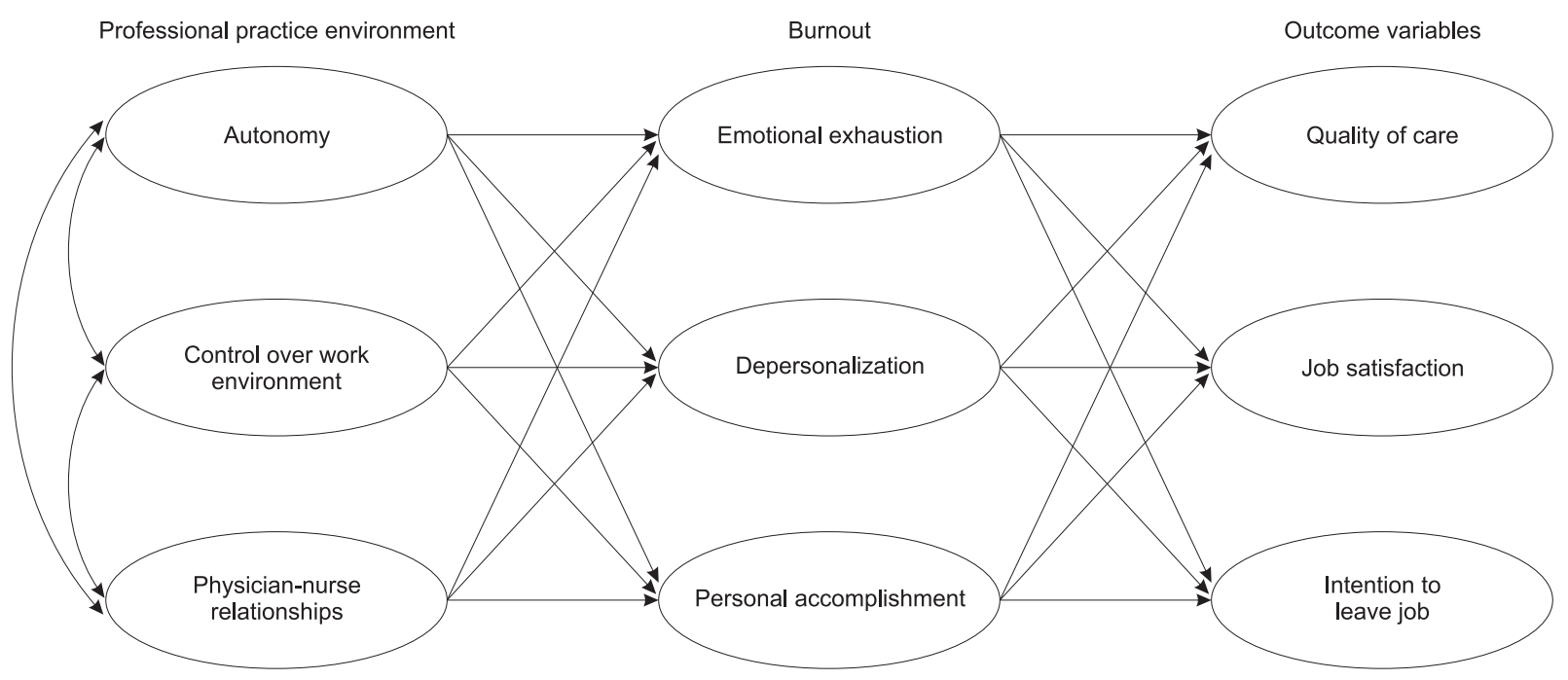

Figure 1 - Causal model of the professional nursing practice environment and outcome variables

The goodness of fit was assessed by adjustment measures of adherence and modification of the model proposed to suggest changes in the structured analyzed. The model was estimated using the unweighted least square (ULS) method.

The main indicators of fitness used were: a) Chi-square ratio ( $\left.\chi^{2} / D F\right)$, should be less than 2.0 to indicate goodness of fit; b) Goodness of Fit Index (GFI), acceptable value is equal to or greater than $0.85 ; \mathrm{c}$ ) GFI Adjusted for Degrees of Freedom (AGFI), acceptable value is equal to or greater than 0.80 ; d) Root Mean Square (RMSR), acceptable value is equal to or less than 0.10 ; e) Root Mean Square Error of Approximation (RMSEA), acceptable value is equal to or less than 0.08 ; f) Bentler's Comparative Fit Index (CFI), acceptable value is equal to or greater than 0.90; and g) Bentler \& Bonett's Non-normed Index (NNFI), acceptable value is equal to or greater than 0.90 .
To analyze how well the data fits the proposed model, significance tests were used. Absolute values for the $\mathrm{t}$ statistics greater than 1.96 indicate that the coefficient associated with the path is significantly different from zero.

\section{Results}

The sample was composed of 129 nurses, $61.2 \%$ of which work in public facilities, $22.5 \%$ in philanthropic facilities, and $16.3 \%$ in private facilities. Among the professionals, $64.3 \%$ work in general ICUs, $16.3 \%$ work in ICUs specializing in trauma and emergency care, $8.5 \%$ in cardiac ICUs, $7 \%$ in transplantation ICUs, and $3.9 \%$ in ICUs specializing in neurology. The individuals' personal and professional characteristics and the characterization of their work environment are presented in Table 1. 
Table 1 - Personal and professional characterization and characterization of professional nursing practice environment in adult ICUs $(n=129)$. Campinas, SP, Brazil, 2012

\begin{tabular}{|c|c|c|c|c|c|}
\hline Variables & $\mathbf{n}$ & $\%$ & $\begin{array}{c}\text { Average (Standard } \\
\text { Deviation) }\end{array}$ & Median & Variation \\
\hline Age & & & $35.1(7.5)$ & 33 & $24-53$ \\
\hline \multicolumn{6}{|l|}{ Gender } \\
\hline Female & 89 & 69 & & & \\
\hline \multicolumn{6}{|l|}{ Marital status } \\
\hline Married & 69 & 53.5 & & & \\
\hline Single & 50 & 38.8 & & & \\
\hline Divorced or separated & 10 & 7.7 & & & \\
\hline Experience in ICUs (years) & & & $4.2(5.0)$ & 2.5 & $0.3-3.8$ \\
\hline Experience in the facility & & & $7.0(6.7)$ & 4.7 & $0.3-26$ \\
\hline Time since graduation (years) & & & $8.4(7.0)$ & 5.0 & $1-27$ \\
\hline Specialization & 85 & 65.9 & & & \\
\hline Residence & 5 & 3.9 & & & \\
\hline Master's or Doctoral degrees & 2 & 1.6 & & & \\
\hline Weekly workload (hours) & & & $50.9(17.5)$ & 40 & $30-92$ \\
\hline \multicolumn{6}{|l|}{ Another job } \\
\hline No & 81 & 62.8 & & & \\
\hline Nurse-patient relationships & & & $9.1(4.3)$ & 8.0 & $2-33$ \\
\hline Nurse-nursing technicians and auxiliary relationships & & & $5.5(3.0)$ & 4.0 & $0-13$ \\
\hline Intention to leave job $(0-10)$ & & & $2.04(2.8)$ & 0.8 & $0-10$ \\
\hline Intention to leave profession $(0-10)$ & & & $1.52(2.7)$ & 0.1 & $0-10$ \\
\hline
\end{tabular}

Job satisfaction and perception of quality of care, both assessed using a Likert scale, are presented in Table 2. Scores concerning poor and very poor assessments were grouped because these were less frequently reported.

Table 2 - Frequency and percentage of job satisfaction and quality of care $(n=129)$. Campinas, SP, Brazil, 2012

\begin{tabular}{lcclcc}
\hline \multicolumn{1}{c}{ Job satisfaction } & $\mathbf{n}$ & \% & Quality of care & \% & 15.5 \\
Very satisfied & 7 & 5.4 & Very good & 20 \\
Satisfied & 84 & 65.1 & Good & 93 \\
Dissatisfied and very dissatisfied & 38 & 29.5 & Poor and very poor & 16 \\
\hline
\end{tabular}

Afterward, the level of burnout and the characteristics of the professional nursing practice environment, obtained through the NWI-R, were evaluated. The averages, standard deviations, medians, and variation of the scores obtained by the subjects in relation to burnout and characteristics of their professional nursing practice environment are presented in Table 3.

Table 3 - Average, standard deviation, median, and variation of the MBI and NWI-R subscales $(n=129)$. Campinas, SP, Brazil, 2012

\begin{tabular}{lcccc}
\hline \multicolumn{1}{c}{ Subscales } & Average & Standard deviation & Median & Variation \\
\hline MBI & & & & \\
Emotional exhaustion & 22.0 & 6.8 & 21.0 & $10-44$ \\
Depersonalization & 9.1 & 2.8 & 9.0 & $5-19$ \\
Personal accomplishment & 30.5 & 4.1 & 30.0 & $20-40$ \\
NWI-R & & & 2.2 & $1-3.6$ \\
Autonomy & 2.2 & 0.62 & 2.3 & $1-3.9$ \\
Control over work environment & 2.4 & 0.60 & 2.0 & $1-4.0$ \\
Nurse-physician relationships & 2.1 & 0.66 & 2.2 & $1.1-3.5$ \\
Organizational support & 2.2 & 0.52 & & \\
\hline
\end{tabular}


Analysis of the correlations among the variables of NWI-R and MBI (perception of quality of care, job satisfaction, and intention to leave job), according to the theoretical model proposed (Figure 1 ), resulted in the following statistics: $\chi^{2} / \mathrm{DF}=2.2, \mathrm{GFI}=0.92$, AGFI $=0.91$, $\mathrm{RMSR}=0.12, \mathrm{RMSEA}=0.09, \mathrm{CFI}=1.0$ and $\mathrm{NNFI}=1.1$. $A$ new specification of model was required due to the high number of residuals indicated by the RMSEA; the acceptable upper limit is 0.08 .
In this context, we opted to use a new theoretical model considering only one of the burnout domains for path analysis: emotional exhaustion. The statistics obtained with this model were: $\chi^{2} / \mathrm{DF}=0.90$, GFI $=0.95$, AGFI=0.94, RMSR=0.07, RMSEA=0.00, CFI $=1.0$ and $\mathrm{NNFI}=1.06$. Estimation of the coefficients revealed the paths were significant, described in Figure 2.

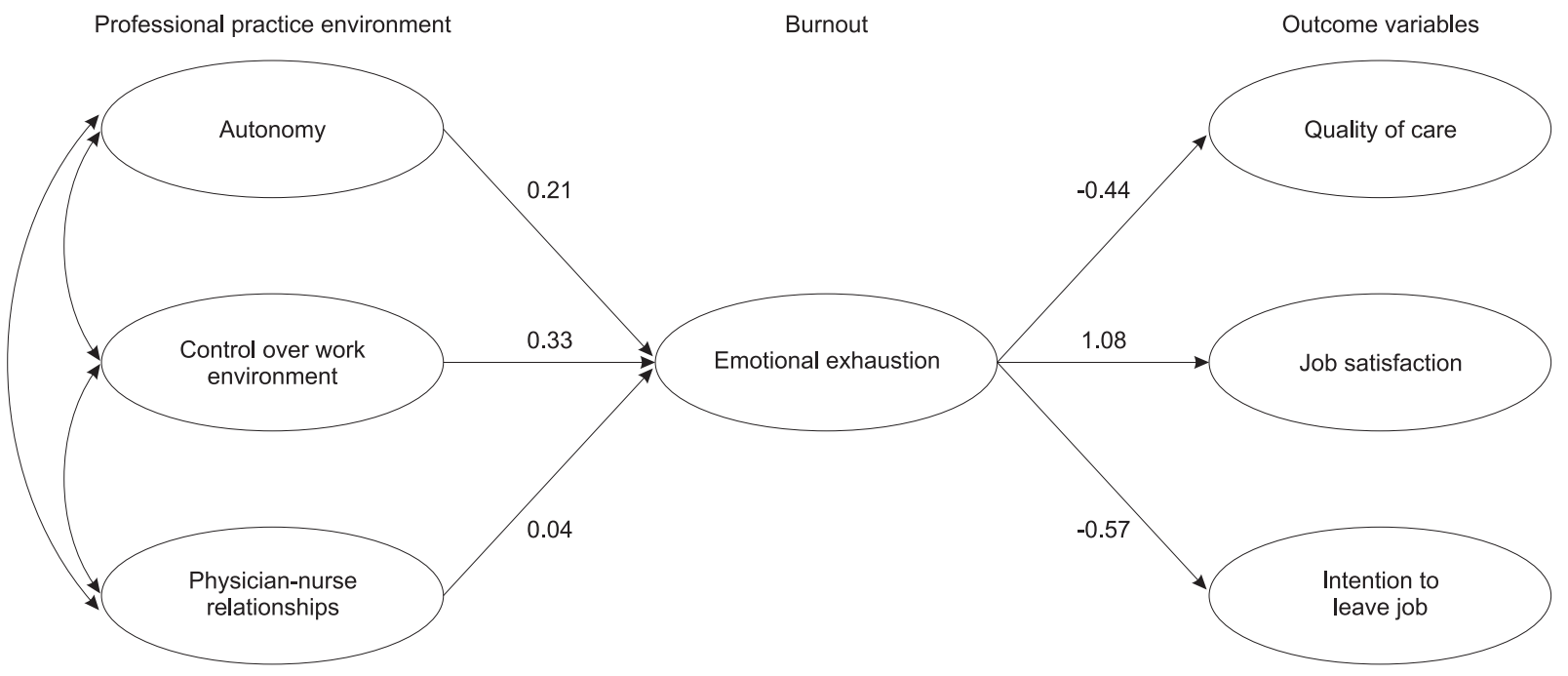

Figure 2 - Final model of correlation of professional nursing practice environment

Figure 2 shows that the characteristics of the environment influence the nurses' perceptions concerning the quality of care, job satisfaction, and their intention to leave their job, when mediated by emotional exhaustion.

\section{Discussion}

The sample was composed of nurses, most working in general ICUs of public institutions. Young adults and women predominate, corroborating results reported by other studies ${ }^{(7-9,13)}$, results that are explained by the historical trajectory of nursing(17).

In regard to the participants' background, most were specialists, with an education level above that reported by studies addressing nurses in other units ${ }^{(13,18-19)}$; time since graduation was also greater than that reported by nurses working in ICUs from other $\operatorname{countries}^{(7,20)}$. In turn, their time of experience is less than that reported by studies addressing adult ICUs ${ }^{(8,20)}$. This is a concern, since lack of experience is associated with higher levels of emotional exhaustion and job dissatisfaction, resulting in poor quality of care delivered to patients ${ }^{(6)}$.

Even though most professionals reported only one job, the average weekly workload reported was 51 hours, which is higher than the workload allowed by the Brazilian Consolidation of Labor Laws(21). The high number of weekly worked hours may be attributed to need on the part of the health service, or on the part of the professionals themselves seeking a higher income.

The nurses reported an average of 5.5 professionals under their supervision and 9.1 patients under their responsibility. The last figure is close to what is recommended by Resolution RDC No. 7, at least one nurse for each eight patients ${ }^{(22)}$. The variation observed in this study, however, indicates there are units in which this resolution is not complied with, where nurses are responsible for up to 33 patients.

In regard to the nurses' intention to leave their job in the next 12 months, the average presented by this study's professionals was below that of nurses working in non-specialized units ${ }^{(13)}$. Even though most nurses 
reported satisfaction with their current jobs, almost $30 \%$ reported being dissatisfied or very dissatisfied. In relation to care, they perceive that the quality of the care provided is good.

The nurses presented a moderate level of burnout on all the subscales: emotional exhaustion, depersonalization, and low personal accomplishment. These findings are similar to studies reporting this level of burnout for the emotional exhaustion domain(15,23), but differ in relation to the depersonalization and personal accomplishment domains. We note that the depersonalization subscale also presented an average above that found in other studies ${ }^{(15,23)}$.

We verified that the scores concerning the participants' evaluation of the characteristics of professional nursing practice environment were below 2.5 points for all the NWI-R's subscales, that is, the professionals reported having autonomy, control over their practice, good physician-nurse relationships, and organizational support.

In regard to the correlations, according to the causal model of the professional nursing practice environment, the initial analyses revealed that, in some cases, goodness of fit was adequate. However, given the large RMSEA, we opted for a new specification of the model, since this is the main index for validation of the causal model. An explanation for its high value may be the number of paths proposed for the studied model. In this sense, we opted for a theoretical model considering the most important construct for burnout, which is emotional exhaustion ${ }^{(10)}$.

Therefore, a new model correlating professional nursing practice environment was specified. This model suggests that the outcome variables may be influenced by the environmental characteristics when mediated by emotional exhaustion. It means that having autonomy, control over their practice, and good physician-nurse relationships may indirectly influence the nurses' perception of quality of care, job satisfaction, and intention to leave their job.

Nurses with limited autonomy, poor control over their practice, and with poor relationships with physicians, experience a greater level of emotional exhaustion, which may negatively influence their perception of quality of care, job satisfaction and intention to leave their jobs.

We highlight the mediating role played by emotional exhaustion. Similar to other studies, this domain mediated the characteristics of environment and depersonalization ${ }^{(9)}$.
This study's results corroborate the findings reported by other studies ${ }^{(2,13)}$ showing that nurses with greater autonomy experience lower levels of emotional exhaustion, which reflects a lower intention to leave their job, greater job satisfaction, and the perception of improved quality of care. Additionally, the presence of autonomy in the professional practice environment of nurses working in ICUs is an important factor in retaining specialized workers, both to promote safe care and to qualify new nurses ${ }^{(24)}$. As noted in a recent study ${ }^{(25)}$, the implementation of strategies designed to promote positive working environments is important to lower levels of burnout, of intentions to leave a job, and job dissatisfaction.

\section{Conclusion}

The professional nursing practice environment, assessed through the NWI-R's variables, was considered to be conducive to professional practice. The multivariate analysis, however, enabled the identification of correlations among the environment characteristics with a direct impact on levels of emotional exhaustion and an indirect impact on the perception of quality of care, job satisfaction, and the intention to leave their job in the next 12 months. We note that emotional exhaustion was the burnout domain that showed the greatest impact on the correlation of the model presented, therefore, indicating a need to adopt strategies that minimize this condition among nurses.

We highlight the importance of further studies proposing other theoretical models to explain the characteristics of professional nursing practice environments and that assess these variables from the perspectives of nurses working in ICUs. The purpose is for nurses to have more support in the literature to devise strategies and propose changes in the professional nursing practice environment. Such changes may result in lower costs for institutions, costs that accrue from errors in care delivery and work leave due to workers' emotional issues.

\section{Study's limitations}

One of the limitations of this study is the fact it was restricted to the ICUs of a single region in the state of São Paulo, Brazil that represents a small sample of the interior of the state. Hence, larger samples and also samples from other regions of the country are required. In relation to the discussion of results, comparison with other studies was hindered since authors do not always 
include all the variables available in the NWI-R and MBI in their analyses.

\section{References}

1. Aiken LH, Sloane DM. Effects of specialization and client differentiation on the status of nurses: the case of AIDS. J Health Soc Behav. 1997;38(3):203-22.

2. Aiken LH, Patrician PA. Measuring organizational traits of hospitals: the revised nursing work index. Nurs Res. 2000;49(3):146-53.

3. Lake ET, Friese CR. Variations in nursing practice environments: relation to staffing and hospital characteristics. Nurs Res. 2006;55(1):1-9.

4. American Association of Colleges of Nursing. Hallmarks of the professional nursing practice environment. J Prof Nurs. 2002;18(5):295-304.

5. Aiken LH, Clarke SP, Sloane DM. Hospital staffing, organization, and quality of care: cross-national findings. Int J Qual Health Care. 2002;14(1):5-13.

6. Kanai-Pak M, Aiken LH, Sloane DM, Poghosyan

L. Poor work environments and nurse inexperience are associated with burnout, job dissatisfaction and quality deficits in Japanese hospitals. J Clin Nurs. 2008;17(24):3324-9.

7. Aiken LH, Clarke SP, Sloane DM, Lake ET, Cheney T. Effects of hospital care environment on patient mortality and nurse outcomes. J Nurs Adm. 2008;38(5):223-9.

8. Stone PW, Larson EL, Mooney-Kane C, Smolowitz J, Lin SX, Dick AW. Organizational climate and intensive care unit nurses' intention to leave. Crit Care Med. 2006;34(7):1907-2012.

9. Van Bogaert $P$, Meulemans $H$, Clarke S, Vermeyen K, Van de Heyning P. Hospital nurse practice environment, burnout, job outcomes and quality of care: test of a structural equation model. J Adv Nurs. 2009;65(10):2175-85.

10. Maslach C, Jackson SE, Leiter MP. Maslach Burnout Inventory Manual. 3rd.ed. Palo Alto: Consulting Psychologist's Press; 1996. 51 p.

11. Shorter M, Stayt LC. Critical care nurses' experiences of grief in an adult intensive care unit. J Adv Nurs. 2010;66(1):159-67.

12. Gasparino RC, Guirardello EB. Tradução e adaptação para a cultura brasileira do "Nursing Work index Revised". Acta Paul Enferm. 2009;22(3):281-7.

13. Gasparino RC, Guirardello EB, Aiken LH. Validation of the Brazilian version of the Nursing Work Index-Revised (B-NWI-R). J Clin Nurs. 2011;20(23-24):3494-501.

14. Tamayo MR. Relação entre a síndrome do burnout e os valores organizacionais no pessoal de enfermagem de dois hospitais públicos [dissertação de mestrado]. Brasília (DF): Universidade de Brasília; 1997. 102 p.

15. Spence Laschinger HK, Leiter MP. The impact of nursing work environments on patient safety outcomes: the mediating role of burnout/engagement. J Nurs Adm. 2006;36(5):259-67.

16. Hair JF, Tatahm RL, Anderson RE, Black W. Análise multivariada de dados. 5th.ed. Porto Alegre: Bookman; 2005. 593 p.

17. Santo TBE, Oguisso T, Fonseca RMGS. The professionalization of brazilian nursing in the written media of the end of the nineteenth century: a gender analysis. Rev. Latino-Am. Enfermagem [periódico na Internet]. set-out 2011 [acesso 15 mai 2012]; 19(5):[07 telas]. Disponível em: http://www.scielo.br/pdf/rlae/ v19n5/pt_26.pdf. Inglês, Português, Espanhol.

18. Lorenz VR, Benatti MCC, Sabino MO. Burnout and stress among nurses in a university tertiary hospital. Rev. Latino-Am. Enfermagem. [periódico na Internet]. nov-dez 2010 [acesso 16 mai 2012];18(6):[08 telas]. Disponível em: http://www.scielo.br/pdf/rlae/v18n6/ pt_07.pdf. Inglês, Português, Espanhol.

19. Roscani ANCP, Guirardello EB. Attention demands in the workplace and the capacity to direct attention of nurses. Rev. Latino-Am. Enfermagem [periódico na Internet]. julho-ago. 2010 [acesso 16 mai. 2012];18(4):[08 telas].Disponível em: http://www. scielo.br/pdf/rlae/v18n4/pt_17.pdf. Inglês, Português, Espanhol.

20. Cho SH, June KJ, Kim YM, Cho YA, Yoo CS, Yun $\mathrm{SC}$ et al. Nurse staffing, quality of nursing care and nurse job outcomes in intensive care units. J Clin Nurs. 2009;18(12):1729-37.

21. Constituição da República Federativa do Brasil de 1988 (BR). Capítulo II - Dos direitos sociais (artigo 70). 1988. [acesso 26 set 2012]. Disponível em: http://www.planalto.gov.br/ccivil_03/constituicao/ ConstituicaoCompilado.htm

22. Resolução RDC No 7, de 24 de fevereiro de 2010 (BR). Dispõe sobre os requisitos mínimos para funcionamento de Unidades de Terapia Intensiva e dá outras providências. 2010. [acesso 2 mai 2011]. Disponível em: http://www.amib.org.br/pdf/RDC-072010.pdf

23. Lin F, St John W, McVeigh C. Burnout among hospital nurses in China. J Nurs Manag. 2009;17(3):294-301.

24. Iliopoulou KK, While AE. Professional autonomy and job satisfaction: survey of critical care nurses in mainland Greece. J Adv Nurs. 2010;66(11):2520-31. 
25. Kutney-Lee A, Wu ES, Sloane DM, Aiken LH. Changes in hospital nurse work environments and nurse job outcomes: An analysis of panel data. Int J Nurs Stud. ahead of print Epub 14 Ago 2012. 